\title{
LAS ADVERSATIVAS Y UNA POSICIÓN AMBIVALENTE EN LA LITERATURA DE CÉsAr AIRA
}

ADVERSATIVES AND AN AMBIVALENT POSITION IN THE LITERATURE OF CÉSAR AIRA

María Belén Riveiro

ORCID 0000-0002-0499-9320

Universidad de Buenos Aires Buenos Aires, Argentina

\section{Resumen}

El presente artículo identifica que uno de los procedimientos que se pueden rastrear a lo largo de la obra de Cesar Aira son construcciones adversativas denominadas "sí, pero no". Estas formas que son mera oposición, uno de los principios generadores de la obra, constituyen un eje iluminador para explorar la posición particular que ocupa Aira en el espacio literario. Esta posición atípica replica su ambivalencia en distintas dimensiones: la figura del escritor, la trayectoria editorial, así como su particular vínculo con la recepción crítica. Estas tensiones que explora el artículo se encuentran en una trayectoria exitosa como la de Aira y, en lugar de romper con los límites literarios, reafirman la creencia en el valor de la literatura.

Palabras clave: literatura argentina; procedimientos; figura de escritor; trayectoria editorial; recepción crítica.

\section{Abstract}

This article suggests that one of the recurrent procedures that can be traced throughout César Aira's oeuvre is the use of adversative constructions, the so-called 'yes, but no'. These phrases, which are used as sheer opposition and are one of the generating principles of Aira's works, offer a key insight into the unique position that Aira occupies in the literary world. This atypical position replicates his ambivalence in various dimensions: the figure of the writer, his publishing trajectory, and his peculiar relationship with critical reception. These tensions, which the article explores, are found in a successful career such as Aira's and,

\section{Resumo}

Este artigo sugere que um dos procedimentos, que podem ser rastreados ao longo da obra de César Aira, são as conjunçôes adversativas chamadas "sim, mas não”. Essas frases consistem em pura oposição e, sendo um dos princípios explicativos da obra, tornam-se uma forma de explorar a posição particular de Aira no espaço literário. Essa posição atípica replica a ambivalência da conjunção em várias dimensôes: a figura do escritor, a trajetória editorial e a relação peculiar com a recepção crítica. Essas tensóes, que o artigo explora, pertencem a uma carreira de sucesso como a de Aira e, ao invés de romper 
instead of breaking literary boundaries, they reaffirm the belief in the value of literature.

Keywords: argentine literature; procedures; figure of the writer; publishing trajectory; critical reception. com os limites literários, reafirmam a crença no valor literário.

Palavras-chave: literatura argentina; procedimentos; figura do escritor; carreira editorial; recepção critica.

Procedimientos en la literatura de Aira: sí, pero no

Uno de los elementos en los que coincide la crítica que lee la obra de César Aira, que en 2018 supera los cien libros ${ }^{1}$, es afirmar que su literatura es rica al punto de lo inasible por lo heterogénea. En general es posible identificar las novelas de un autor con un tema, una propuesta literaria o un estilo, entre otras categorías. Los libros de Aira aparecen como creaciones únicas que no conviven entre ellas como un conjunto. De manera temprana, Diana Sperling encuentra en la obra de Aira un "amplio espectro, tanto en el nivel temático como en el formal" (1984, p. 1). El propio Aira abona esta idea: "No sé si es un defecto o una virtud, pero hay un efecto camaleónico que me produce la lectura. Todo me gusta, con todo me identifico" (AIRA, 1993b, p. 4). Sandra Contreras (2002) construye la categoría de ciclos para agrupar los libros en vinculación con ciertos temas: el ciclo pampeano (al que corresponden Moreira y La liebre, por ejemplo), el ciclo darwiniano ( $\mathrm{La}$ liebre, Embalse, La guerra de los gimnasios, Los misterios de Rosario) y el ciclo televisivo (La luz argentina, Embalse, La liebre), entre otros. Sin embargo, no son categorías excluyentes ni tampoco permiten aprehender la totalidad de la obra.

Más allá de esta heterogeneidad, una y otra vez se repite el foco en los procedimientos que Aira pone en juego en sus novelas. También el propio Aira apunta a los procedimientos como parte de su clave de escritura y propuesta de lectura: "Me refiero al procedimiento en su acepción más común, a tener una técnica explícita" (AIRA 1993a, p. 2). Entre otros procedimientos, formula el del continuo: "Empieza siendo el continuo entre la forma y el contenido, pero prolifera a todo absolutamente (...) Esa es una idea a la que he vuelto ahora con mucha fuerza, la del mundo que se transforma en mundo. Eso lo puse en La prueba" (AIRA, 1992, p. 9). La huida hacia adelante: "La huida hacia adelante es para mí una redención del pasado. Tengo que redimir tantas

1 Ese mismo año, Ricardo Strafacce publica César Aira, un catálogo (2018a) donde, en sintonía con la lógica de la curaduría de una muestra de arte, selecciona una página de cada uno de los cien títulos junto con la respectiva tapa. 
novelitas chistosas que no me va a alcanzar el presente" (AIRA, 1993b, p. 5). Y el abandono: "El abandono es una fantasía que está en todo artista. Es también una vieja idea mía. Si uno puede llegar a ser artista, ¿para qué molestarse en hacer cosas?" (AIRA, 1993a, p. 2). En "La nueva escritura", texto publicado en 1998 en la publicación mexicana La jornada semanal, propone sin más que el procedimiento es el fundamento del arte.

En su tesis doctoral ${ }^{2}$, Contreras (2002) detalla los procedimientos del arte narrativo de Aira con los que da continuidad al relato, trabaja con los estereotipos, acelera las historias y confecciona su tradición literaria. En base a un consenso sobre el elemento vanguardista en el proyecto de Aira (MONTALDO, 2005; PRIETO, 2005; VECCHIO, 2005), posteriores estudios se centran y desarrollan los procedimientos de sus novelas: el continuo (PODLUBNE, 1996), la miniatura (LADDAGA, 2001; KOHAN, 2005; MANZI, 2005), el continuo y la hibridación genérica (GARCÍA, 2006), el abandono y el continuo (MARQUARDT, 2008), entre otros.

En este artículo parto en uno de los elementos que se repite de manera frecuente en las novelas de Aira. Me refiero a las construcciones adversativas que Strafacce denomina "sí, pero no" (1998a, p. 51). Es posible hallar estas oraciones a lo largo de la obra de Aira. Con fines ilustrativos cito algunos libros, al menos uno por cada lustro de los publicados entre 1981 y $2020^{3}$ : "Hablaba y hablaba, con una voz que era serena por porvenir de un gran cuerpo pesado, y ya fuera por la fuerza de sus palabras o por una singularidad del estado histérico de Kitty, el sueño siempre acudía, simple, lento y a la vez instantáneo" ( $L a$ luz argentina, Centro Editor de América Latina, Buenos Aires, 1983, p. 91); "O le parecía que era demasiado tarde, o que era demasiado temprano; y cuando no le parecía ni una cosa ni la otra, le parecían las dos a la vez" (Una novela china, Javier Vergara Editor, Buenos Aires, 1987, p. 83); "mi cuerpo fluye por una materia homogénea, de oscuridad sin lo oscuro y de claridad sin la luz" (El llanto, Beatriz Viterbo, Rosario, 1992, p. 8); "En aquel entonces el chiste era nuevo. Me dirán que ese chiste siempre fue viejo. De acuerdo, pero aun así era nuevo" (Los dos payasos, Beatriz Viterbo, Rosario, 1995, p. 21-22); "Lo mecánico de su producción descartaba cualquier variante, pese a lo cual siempre era distinto" (La pastilla de hormona, Belleza y Felicidad, Buenos Aires, 2002, p. VII); "El problema del mal comportamiento puede deberse al hecho de que Dios no preside la mesa. Mejor dicho, preside y no preside" (El té de Dios, Mata-mata ediciones latinoamericanas, Guatemala, 2010, p. 17); "Es por eso que todo acercamiento será al mismo tiempo un alejamiento" (Actos de

2 La tesis fue dirigida por Nicolás Rosa y defendida en 2001 en la Facultad de Filosofía y Letras de la Universidad de Buenos Aires frente a un jurado compuesto por Ana María Camblong, Beatriz Sarlo y Susana Zanetti. En 2002 se publica con el título Las vueltas de César Aira en la editorial Beatriz Viterbo. 3 En 1981 circulan por primera vez libros de Aira (STRAFACCE, 2008a; RIVEIRO, 2020). 
caridad, Hueders, Chile, 2014, p. 30); "Quizás adivinando mi predicamento futuro, veía en él la solución perfecta a los problemas de la ocupación del tiempo: estaba sembrado de metas, tan lejanas como las quisiera y a la vez todas al alcance de la mano" (Prins, Literatura Random House, Barcelona, 2018, p. 37); "El Pelícano, debido a su aparición súbita a su vez debido a su desaparición, paradoja que tenía algo de magia blanca, renovó en ellos esta dialéctica" (El Pelícano, Mansalva, Buenos Aires, 2020, p. 16).

La categoría ad hoc para referirse a estas construcciones adversativas como "sí, pero no" que formula Strafacce se vuelve necesaria porque su forma no parece corresponder a las clasificaciones de la gramática. María Marta García Negroni en su Manual de corrección de estilo (2004) explica que existen dos tipos de conjunciones de coordinación adversativas: en una los términos opuestos no son incompatibles y su oposición puede ser directa o indirecta ("Es político, pero es honesto", ejemplifica para las adversativas restrictivas) y en la otra el segundo elemento niega al primero ("No vino ayer sino hoy" es ejemplo de una conjunción adversativa exclusiva). En ambos casos se trata de una construcción binaria que establece una oposición en la que tiene preeminencia el segundo término. En las adversativas que emplea Aira hay mera oposición, exposición de las contradicciones, sin interés ni posibilidad de dar preeminencia a un término sobre el otro.

Strafacce (1998a) rastrea una genealogía de este recurso en la literatura de Franz Kafka. La define como un devenir hacia aquello que el lenguaje no puede representar, hacia un umbral que constituye el momento en que Kafka "interrumpe las novelas" (STRAFACCE, 1998a, p. 55). El "sí, pero no" supone el devenir del lenguaje en otra cosa, el rechazo de la posibilidad del lenguaje de representar el mundo; en definitiva, la presencia del lenguaje: "Las palabras en Kafka se sacan la lengua” (STRAFACCE, 1998a, p. 54). Sylvia Saítta, en sus años de estudiante y becaria de investigación, identifica este "juego de inversión" de manera temprana en una reseña de Una novela china publicada en la revista Los días del viaje. "El principio constructivo del texto" es una "estructura oracional" que "juega permanentemente con la afirmación y la negación simultánea: el texto se dice y se desdice” (SAÍTTA, 1988, p. 47). El efecto es de "incertidumbre donde todo es de un modo, pero podría no serlo" (SAÍTTA, 1988, p. 47). Saítta encuentra en esta "imposibilidad de asir" la realidad y en la "lectura desestabilizante" la belleza del texto (1988, p. 47).

Esta construcción ambivalente, propongo, puede entenderse como uno de los principios generadores de la obra por su presencia multiplicada y porque se trata de un eje iluminador para explorar la posición particular que ocupa en el espacio literario. Esta posición atípica replica su ambivalencia en distintas dimensiones: la figura del escritor, la trayectoria editorial, así como su particular vínculo con la recepción crítica. El análisis, de este modo, 
supone abordar la obra y también variables sociológicas que no sólo no se restringen a las características intrínsecas del objeto de estudio, sino tampoco sólo a dimensiones sociales de la producción literaria, como la editorial o la recepción, entendidas como factores explicativos de manera independiente. Supone, sobre todo, una mirada relacional que aborda la singularidad, en este caso de un autor y su obra, que cobra sentido en comparación con las particularidades de otros escritores y proyectos literarios contemporáneos y de otras posiciones posibles (MICELI, 2017).

\section{Un revolucionario secreto: figura del escritor, trayectoria editorial y recepción}

Esta posición ambivalente se puede rastrear, en primer lugar, en los modos en que Aira se presenta en público como escritor. ${ }^{4}$ De manera contundente, desde los inicios de su trayectoria como escritor editado, Aira afirma "yo nunca usaría la literatura para pasar por una buena persona" (AIRA, 1982, p. 2). Se distancia de la figura de la literatura comprometida, imagen central en los años sesenta y setenta, cuando se debilitan las mediaciones entre el campo literario y el político (DE DIEGO, 2007), o de una escritura que sigue el deber de oponer resistencia "al canibalismo de los medios de comunicación y a la trivialización que impone la industria cultural" (DE DIEGO, 2007, p. 277) como la que comienza a valorarse durante la transición democrática en Argentina, dado que permite reformular el vínculo entre literatura y política. Esta última propuesta la encarna la obra de Juan José Saer, que se vuelve central para la crítica en los años ochenta (DE DIEGO, 2007; DALMARONI, 2010).

En discusión con estas miradas que proponen un compromiso social o político, Aira propone un compromiso con la literatura. "El umbral es el amor a la literatura (no hablo de respeto, porque la literatura es tan grande y soberana que ni siquiera hay que respetarla), por más que eso nos lleve lejos de nuestros deberes sociales y morales. Es preferible volverse un payaso" (1982, p. 3) propone Aira en 1982, en la primera entrevista que otorga como escritor, publicada en la revista Pie de página. Así funda una "moral utópica de escritor" (LIBERTELLA, 2006, p. 59) en sintonía con la construcción de una tradición de escritores marginales como Osvaldo Lamborghini y Copi. ${ }^{5}$

No obstante, este compromiso con lo literario carece de rigor, es un gesto cercano a la sonrisa seria que menciona Aira en numerosas novelas. Cuando comenta que aspira a la trascendencia de la "gloria", se apura a adjetivarla como "de bolsillo" (AIRA, 1984, p. 1). Cuando confirma su vínculo

4 Exploré esta dimensión mediante el análisis de entrevistas otorgadas por Aira en Riveiro (2019).

5 Trabajo algunas ideas en torno a la construcción de la tradición literaria de Aira en Riveiro, 2020. 
con la vanguardia, al instante se desdice: "De todas formas yo me considero un escritor de vanguardia por supuesto (risas)” (AIRA, 1983, p. 8). ${ }^{6}$ Resulta esclarecedora esta ambivalencia cuando se la contrasta con propuestas de experimentación literaria, con las que se lo suele identificar y con las que se identifica Aira mismo, como la de un escritor cercano a su posición y valorado por él, Osvaldo Lamborghini. ${ }^{7}$ En tanto comparten características y miradas en torno a la literatura ${ }^{8}$-Lamborghini participa de la revista Literal que aboga por la autonomía de la literatura y encuentra su potencia en el trabajo con el lenguaje (IDEZ, 2010)-, se trata de un contraste privilegiado para observar cómo miradas similares no se traducen necesariamente en posiciones idénticas.

Lamborghini crea una obra que desafía ciertos consensos y que, cercano a Aira, "jamás se planteó seriamente 'adaptar' su escritura a las condiciones de recepción y lectura imperantes" (STRAFACCE, 2008b, p. 359). Este desafío literario se traduce en otros ámbitos de su trayectoria, como cuando pierde interés por publicar y logra abocarse a la escritura; se vuelve a un "ensimismamiento, que hacía sistema con la decisión de ya no salir a la calle tomada un tiempo atrás" (STRAFACCE 2008b, p. 809). A ello se puede sumar el hecho de que su trayectoria laboral en talleres y redacciones no es estable, lo que contrasta de manera tajante con Aira, quien consolida una carrera laboral como traductor que le da independencia económica y a la vez le permite dedicarse a la escritura. ${ }^{9}$ Es por eso que se presenta como "pequeño burgués" (AIRA, 2016). Esta posición también parece chocar con

6 Cabe mencionar muy brevemente cierta similitud de este gesto ambivalente de Aira con la figura que encarna Jorge Luis Borges con el movimiento en que traduce el estilo de Sur-marcado por un ensayismo como "subterfugio intelectual legítimo para hacer política a la distancia" (MICELI, 2017, p. 75)- en "combustible de acertijos ficcionales" (MICELI, 2017, p. 91). La literatura de Borges, su mezcla de materiales y estrategias de la cultura masiva (como el género policial) y el material erudito que exige desciframientos por parte de los críticos y lectores, "era el modo tortuoso de reciclar los topos de la tradición ensayística sin abdicar del estatus extraterrestre de la obra literaria, como si el material ficcional así creado pudiera valer como sucedáneo, más que perfecto, del mundo social abjurado" (MICELI, 2017, p. 101).

7 Para un exhaustivo trabajo sobre la vida y la obra de Osvaldo Lamborghini, véase Strafacce, Ricardo. Osvaldo Lamborghini, una biografia (2008b).

8 "Su coherente y permanente rechazo de todo progresismo, su abjuración estética de todo arte 'comprometido' y su incansable inclinación por incomodar y descolocar al que lo escuchara, lo habían llevado muchas veces a probar, y a probarse, cuáles eran los límites de lo que se podía decir, tal como había hecho en sus dos libros publicados, donde no hacía sino tantear los límites de lo que se 'podía' escribir" (STRAFACCE, 2008b, p. 424)

9 Aira se presenta a una prueba de traducción de la editorial Paidós a principios de los setenta. Desde los ańos sesenta las editoriales argentinas traducen gran cantidad de libros e incorporan traductores en medio de la efervescencia de las publicaciones de Psicología y Ciencias Sociales (AGUADO, 2014; FALCÓN, 2017) con el trasfondo del movimiento modernizador del que las universidades son protagonistas. Esto supone la posibilidad, para "numerosos intelectuales jóvenes", de "dedicarse de manera más o menos directa al desarrollo de sus carreras intelectuales, como un ámbito de profesionalización en las tareas editoriales" (DUJOVNE 2016, p. 136). Desde estos años hasta principios del siglo XXI Aira no deja el trabajo de traductor. 
las libertades y desafíos que propone su obra. Esa "moral utópica de escritor", que define Libertella (2006, p. 59) para Aira, no tiñe todos los aspectos de su vida, como sí pudo suceder con figuras como Lamborghini.

Como modo de conciliar la ambivalencia entre la figura del pequeño burgués con un rupturista en lo literario, Aira escapa a las posibles contradicciones con la figura del "revolucionario secreto" que toma de Aldo Pellegrini. Lo conoce personalmente cuando se muda en 1967 desde su Coronel Pringles natal a la ciudad de Buenos Aires. Pellegrini es el librero de la librería "El Dragón” y el vínculo que por esos años se establece con estos libreros no se reduce a la transacción comercial, sino que es un lazo más cercano de recomendación de lecturas, de creación de redes con otros escritores, editores y libreros, de acceso a producciones extranjeras y de intercambio de ideas. Este librero, que le abre en su juventud el mundo surrealista con su Antología de la poesía surrealista de lengua francesa (Compañía General Fabril Editora, 1961), parece adelantarle a Aira la posibilidad de conciliar una trayectoria laboral estable, como la traducción, con la dedicación a un proyecto literario que por esos años setenta solo encontraba rechazos en editoriales (RIVEIRO, 2020):

En los años sesenta, Pellegrini tenía una pequeña librería, y a los jóvenes que íbamos a comprarle libros surrealistas nos predicaba su teoría del 'revolucionario secreto' (ponía por ejemplo a Mallarmé): correctos ciudadanos y buenos padres de familia por fuera, destructores del orden establecido cuando se sentaban a escribir (AIRA, 2001, p. 23-24).

A este primer aspecto de la posición ambivalente en torno a la figura del escritor, se le puede sumar un segundo elemento en torno a la trayectoria editorial de Aira. Mientras que para mediados de los años noventa Aira se distancia de las instancias públicas, deja por unos años de dar entrevistas a publicaciones periódicas; participa solo en unos pocos eventos literarios y alimenta la figura del escritor oculto; es decir, mientras minimiza su presencia contrapone a ello otra figura con la que se lo identifica, que es la de escritor prolífico.

La proliferación editorial se refiere al hecho de que Aira llega a publicar más de cuatro títulos por año en editoriales de diversas características. ${ }^{10}$ Por ejemplo, la solapa de El juego de los mundos (El broche, Buenos Aires, 2000) advierte: "Es un dato biográfico la aparición de tres o cuatro libros anuales que llevan su firma. El juego de los mundos cierra, en este caso, la extensa lista.

10 En 2011 llega a publicar diez títulos: A Brick Wall (Del centro editores, Madrid); Cecil Taylor (Mansalva, Buenos Aires); El criminal y el dibujante (Spiral Jetty, Buenos Aires); El hornero (Sazón Ediciones Latinoamericanas, Santiago de Chile); El mármol (La bestia equilátera, Buenos Aires); El náufrago (Beatriz Viterbo, Rosario); En el café (Belleza y Felicidad, Buenos Aires); Festival (Edición del 13 Buenos Aires Festival Internacional de Cine Independiente / BAFICI, Buenos Aires); La revista atenea (Sazón Ediciones Latinoamericanas, Santiago de Chile); y Los dos hombres (Urania, Buenos Aires). 
Por poco tiempo." Resulta ilustrativo el año 2001, cuando Aira participa de los tres grandes grupos editores transnacionales: el grupo Planeta que en 2000 compra Emecé (La villa, 2001), Random House Mondadori que en 2001 firma la unión que crea este conglomerado (Cumpleaños, 2001) y el grupo Santillana que en 1980 compra Alfaguara (Un sueño realizado, 2001). En simultáneo publica en "editoriales medianas y pequeñas de capital local" (SAFERSTEIN y SZPILBARG, 2012) como la rosarina Beatriz Viterbo (Las tres fechas, 2001).

Sobre esta práctica reflexiona Montaldo, quien explica que "desde el margen editorial satura el mercado de textos marca Aira" (1998, p. 14). Contreras (2002) identifica que, desde comienzos de los ańos noventa, comienza a funcionar la "máquina" de producir "novelitas". Retoma el análisis de Montaldo de la "superproducción a-mercantil artesanal" (MONTALDO, 1998, p. 14), que lee junto con la categoría del continuo de Aira, para definirlo como un fenómeno de publicación "indiscriminada" que se contrapone a valores dominantes identificados con la práctica del escritor signada por la clandestinidad y la lentitud, cuyo paradigma es Macedonio Fernández, quien reserva su obra para la posteridad.

Con esta presencia asidua, múltiple y en espacios heterogéneos del campo editorial, Aira trastoca la identidad entre un editor o editorial con el escritor. Las editoriales suelen entablar vínculos de exclusividad con los escritores. De hecho, cuando un autor pasa de un catálogo a otro se vuelve noticia. Como en el fútbol, el "mercado de los pases" no pasa desapercibido: "Bioy Casares, de Tusquets a Emecé; Borges, de Emecé a Seix Barral” a lo que se suma la intriga de "un escritor exitoso que Sudamericana guarda en secreto con el cual piensa sorprender en abril a un mercado cada vez más competitivo" (RUSSO, 1995, p. 44). No son casos aislados. Las editoriales se disputan a los escritores. Así se relata que "Emecé viene de ganar reñida pulseada con Biblioteca del Sur, esa suerte de milagro que Planeta supo conseguir. El botín era la nueva y aparentemente monumental novela de Abelardo Castillo" (Página/12, 1991, p. 6). Aira no es ajeno a este fenómeno. En 1999, Página/12 anuncia que "fue convocado por la editorial Alfaguara para discutir las condiciones de su incorporación al catálogo de ese sello. Hay Aira para todo" (1999, p. 2).

Sin embargo, no es posible identificar a Aira, en ningún momento de su trayectoria, con un editor en particular ni tampoco con un tipo de editorial. Hopenhayn recurre a la figura del marketing para reflexionar en 1998 sobre los modos en que Aira tiene una "doble vida editorial con la que parece sostener una política de sí mismo" (HOPENHAYN, 1998, p. 7). En contraste con ello, "ninguna editorial ni medio de comunicación puede tentarlo tanto como para hacerle perder su autonomía" (HOPENHAYN 1998, p. 7). Aira parece nunca llegar a trazar el camino de "profesionalización" que 
sí recorre otro escritor central en los ochenta como es Saer, cuya consagración se funda, en parte, por este vínculo editorial (DALMARONI, 2010). Saer, tras "esa modalidad errabunda" de publicación en editoriales diversas, pasa a Alianza editorial y después a Seix Barral del Grupo Planeta porque entabla una relación sólida con el editor Alberto Díaz, quien comienza a trabajar en Seix Barral (DALMARONI, 2010, p. 660).

En breve, este vínculo con la dimensión editorial es ambivalente. Aira se define como un escritor oculto ajeno a las instancias públicas pero su presencia en el mercado editorial es multiplicada. Aira tiene una presencia clara en el mercado editorial, pero es imposible identificarlo en ningún momento de su trayectoria con un editor o con una editorial en particular.

El último punto en el que se enfoca el presente artículo para explorar la posición ambivalente de Aira es la recepción crítica. Mientras que el mercado editorial y el espacio de la crítica parecieran detentar y regirse por lógicas diferentes, así como ocupar polos opuestos dentro del espacio literario, en el caso de Aira se encuentra que no sólo tiene una presencia privilegiada en el espacio editorial, como se ha visto, sino también una buena recepción crítica-sobre todo a fines de los años noventa y comienzos del siglo XXI. Y esta recepción es, a su vez, ambivalente.

Antes de pasar a estas instancias de recepción, cabe mencionar un caso de un escritor en el que se puede vislumbrar cómo la dimensión mercantil y el éxito en lo editorial parecen contradecir la calidad literaria de la obra. En los años ochenta, Jorge Asís tiene una presencia llamativa ${ }^{11}$ en publicaciones periódicas y listados de best sellers mientras que recibe en su mayoría críticas negativas. El hecho de ser best seller no es valorado, a diferencia de los ańos sesenta, cuando esto se puede leer como un acercamiento del escritor con el público general; un hecho deseable, que ahora cuando la dimensión mercantil asoma a la superficie, va en detrimento de lo literario.

El caso de Aira, con plena presencia en el mercado, coincide con un proceso de valorización por parte de la crítica entre otras instancias de otorgamiento de prestigio del espacio literario. Aira tiene una amplia recepción en la academia y en publicaciones periódicas como revistas literarias y suplementos culturales de diarios, así como en tesis dedicadas a su obra que se basan en el sobreentendido de la relevancia particular de esta literatura ${ }^{12}$.

11 Hasta Borges, conocido por no dar su opinión sobre sus contemporáneos - "Mi literatura no tendrá herederos" dijo en el teatro Auditorium de Mar del Plata ("Borges dijo ser un escritor sin herederos", Convicción, Buenos Aires, 2 de agosto de 1983, p. 24)- opina "yo tengo la convicción de que la mayoría de los escritores son muy superiores a mí (...) Ahora, desde luego, creo que puedo ser superior a un señor que se llame Asís, por ejemplo" (BORGES, 1982, p. 3).

12 Entre muchos de los trabajos aparecen el artículo de Adriana Astutti ("Un nińo en la biblioteca nacional". Revista de Letras, n5, Rosario, 1997, p. 37-43); el artículo de Graciela Montaldo donde lo compara con Jorge Luis Borges ("Borges, Aira y la literatura para multitudes", Boletin/6, Rosario, 1998) 
A esta recepción positiva se suma que Aira cuenta con numerosos premios: entre otros, en 1989 es finalista del concurso Clarín-Aguilar por La liebre, novela por la que en 1992 recibe el premio Boris Vian entregado por escritores y presentado como "antipremio" (Página/12, 1987, p. 9) opuesto a premios oficiales como, justamente, el Clarín-Aguilar; en 2001 recibe una mención del premio Konex a la novela del quinquenio 1989-1993; en 2013 recibe el premio a la trayectoria del Fondo Nacional de las Artes; en 1996 traspasa las fronteras nacionales y gana la Beca Guggenheim; en 2014 gana el Premio Roger Caillois en Francia; en 2016, el Premio Iberoamericano de Narrativa Manuel Rojas en Chile; y en 2021 el premio Formentor en España. Es un autor muy traducido (en una recopilación de datos sobre traducciones de libros de Aira es posible encontrar que se lo traduce a 25 idiomas en cerca de 40 países y que desde 2000 no pasa un año sin que se traduzca uno de sus títulos). Ocupa un lugar central en editoriales (en 2011 la editorial Emecé crea la Biblioteca César Aira, al igual que lo hace Literatura Random House en 2015; en 2019 la editorial de capitales nacionales Blatt $\&$ Ríos presenta su Biblioteca César Aira).

Como sucede con las anteriores dimensiones, el vínculo de Aira con estas instancias prestigiadoras es ambivalente. Mientras que la recepción coincide en afirmar el valor de su obra, de manera simultánea lo considera un autor inasible que lleva a una reformulación de las nociones vigentes con las que se piensa la literatura. Su literatura resulta "ininteligible" (MONTALDO, 1998) y "misteriosa e inasible" (REMÓN RAILLARD, 1999, p. 380). La crítica se encuentra frente a un interrogante imposible: "¡cómo describir entonces una literatura que se resiste a cualquier principio de orden y diferenciación?” (SPERANZA, 2001, p. 8) y llega a afirmar que Aira es una "anomalía" (VANOLI, 2011). Tomás Abraham y Martín Kohan coinciden en el efecto que causa la lectura de la obra de Aira. Para Abraham, Aira es "una experiencia de lectura" con "imágenes imprevistas que detienen la lectura y reordenan la

\footnotetext{
-ya en 1990 Montaldo publica un artículo en el que escoge a Aira entre otros escritores para estudiar la literatura argentina de la década anterior ("Un argumento contraborgiano en la literatura argentina de los años 80 (Sobre C. Aira, A. Laiseca y Copi)”, Hispamerica. Revista de Literatura, ${ }^{\circ} 55$, Universidad de Maryland, 1990, p. 105-12); el libro de Laura Estrín (César Aira. El realismo y sus extremos. Buenos Aires: Ediciones del Valle, 1999); la tesis doctoral de Margarita Remon-Raillard (César Aira o la literatura del continuo, Grenoble III, 1999); el libro de Nancy Fernández (Narraciones viajeras. César Aira y Juan José Saer. Buenos Aires: Biblos, 2000) y su posterior tesis doctoral (Escrituras de lo real: César Aira y Arturo Carrera. Universidad Nacional de La Plata, Facultad de Humanidades y Ciencias de la Educación, 2005); el artículo que se propone desafiar las categorías convencionales de la crítica para abordar la obra de Aira escrito por Graciela Speranza para Milpalabras. Letras y artes en revista, "César Aira. Manual de uso", $\mathrm{n}^{\circ} 1$; la tesis doctoral de Sandra Contreras defendida en 2001 y su publicación como Las vueltas de César Aira. Rosario: Beatriz Viterbo 2002; el artículo de Reinaldo Laddaga ("Una literatura de la clase media: notas sobre César Aira”, Hispamérica - Revista de literatura, nº8, Ediciones Hispamérica, 2001); y los textos de Silvio Mattoni ("César Aira. Una introducción". In AAVV. Umbrales y catástrofes: literatura argentina de los '90. Córdoba: Epoké ediciones, 2003) y de Mariano García (Degeneraciones textuales. Los géneros en la obra de César Aira. Rosario: Beatriz Viterbo Editora, 2006).
} 
estantería” (2004, p. 135). Kohan, de manera similar, encuentra que tanto la escritura como la figura de escritor de Aira "han venido desacomodando los parámetros de lectura que imperaban en la literatura argentina" a punto tal que "hubo que inventar por completo el lugar desde donde convenía leer su obra" (KOHAN, 2005, p. 79). Aira pone "en duda los criterios y mecanismos de lectura y evaluación estética” (PREMAT, 2005, p. 43) o, tomando en préstamo la teoría de Jacques Derrida, produce una "desarticulación constante, que instaura una différance" (GARCÍA, 2006, p. 17). Los libros de Aira son una de las "formas del desconcierto" (MONTALDO, 2004, p. 48) que introducen una novedad que "parece subvertir nuestras hipótesis de lectura" (DECOCK, 2014, p. 1). Como epítome de este efecto desorientador se afirma que se trata de una obra "desmedida e inclasificable" (LO PRESTI, 2014).

Menciono una última ambivalencia, si bien Aira desdeña las instancias de consagración -en una entrevista antes citada menciona que busca una gloria, pero de bolsillo-, también se interesa por ciertas mediaciones como cuando le piden su opinión sobre los premios literarios y comenta: "Me gustaría ganar uno que tuviera una buena dotación económica” (AIRA, 2002). Muy diferente es la relación que propone Piglia, a comienzos de los años ochenta, de un rechazo sin más a estas instancias: "Ganar un concurso es algo que a todo escritor argentino le ha pasado alguna vez, al comienzo, en el medio o al final, siempre se termina por recibir algún premio. Es una humillación por la que uno tiene que pasar, como diría Gombrowicz, si quiere ser un escritor realmente argentino" (PIGLIA apud DÁMASO MARTÍNEZ, 1985, p. 9). El gesto de Aira, que hace resaltar la dimensión económica de una instancia como la premiación que pareciera ser primordialmente simbólica en lugar de socavar el valor de lo literario, de manera inversa y quizás contraintuitiva, resalta la dificultad de estas instancias de consagración de aprehender un supuesto valor puro de lo literario, que las excede. ${ }^{13}$

\section{Si la felicidad existe está en los extremos ${ }^{14}$}

Para concluir, resulta relevante dar cuenta de la pertinencia del estudio de este caso que vuelve estas ambivalencias una posición y propuesta

\footnotetext{
13 Vale citar un análisis que realiza Pierre Bourdieu en torno al vínculo de Charles Baudelaire con su candidatura a la Academia Francesa, que tiene un vínculo similar con las instancias de consagración: "Al presentar su candidatura a una institución de consagración que todavía goza de amplio reconocimiento, Baudelaire, que es el que menos ignora la acogida que le van a dispensar, afirma el derecho a la consagración que le confiere el reconocimiento que se le tributa en el estrecho círculo de la vanguardia; al obligar a esta instancia desacreditada en su opinión a manifestar abiertamente su incapacidad para reconocerlo, afirma también el derecho, e incluso el deber, que recae en aquel que ostenta la nueva legitimidad, de trastocar la tabla de valores, obligando a aquellos mismos que le reconocen, y a los cuales su acto desconcierta, a confesarse que siguen reconociendo el antiguo orden más de lo que creen." (BOURDIEU 2005, p. 101)
} 14 Extraído de Lucio V. Mansilla, Una excursión a los indios ranqueles (1870). 
literaria reconocida. Se citaron instancias de consagración como premios y traducciones, pero la consagración no es un fenómeno simple de aprehender (BOSCHETTI, 2014), sobre todo en un campo literario con instituciones y autoridades débiles y fluctuantes como el de Buenos Aires; incluso como el latinoamericano que, desde los años ochenta y noventa sufre modificaciones. Fernando Escalante Gonzalbo (2007) explora estas transformaciones y propone que la singularidad del presente no es el empobrecimiento de la diversidad literaria (se produce cada vez más y con estéticas divergentes), sino la escasez de lo que llega a los lectores que, a su vez, son un público restringido, cada vez más marginalizado y fragmentado. A ello se suma que se hacen borrosos los criterios que utilizan los lectores para distinguir entre los libros buenos y malos dado que la estructura de mediaciones que configuran la práctica de la lectura ve en crisis su legitimidad porque "la misma corporación (...) hace los libros, las reseñas y otorga los premios, y con estos recursos produce la fama, el prestigio de los intelectuales que es lo que finalmente sirve para vender sus libros" (ESCALANTE GONZALBO, 2007, p. 42) Los criterios de evaluación se vuelven "publicidad editorial" (ESCALANTE GONZALBO, 2007, p. 41) y, como quedan en sospecha estos mecanismos, lo que está en juego es el mismo valor simbólico de la literatura.

Lo productivo del estudio de la posición de Aira es explorar un caso que con sus ambivalencias refuerza la creencia en este valor que aparece como erosionado. El relato de Contreras sobre su vínculo con la literatura de Aira es iluminador:

El mismo hecho de que la literatura de Aira se fuera imponiendo, al menos en el contexto de la literatura argentina, como un punto de vista excluyente, absoluto, creando sus propios paradigmas, hizo que en el trabajo se tratara no sólo de querer pensar la emergencia de ese punto de vista sino también de pensar desde allí, de querer pensar y usar los conceptos, las relaciones críticas, las filiaciones y los contrastes, desde el punto de vista Aira (CONTRERAS, 2003, p. 1).

Así, tomar a Aira como autor no supone explicar todo Aira, sino leer "el cuento inventado por la ficción de Aira" (CONTRERAS, 2003, p. 10). Contreras agrega, dando cuenta de la vitalidad de este encuentro entre sus interrogantes teóricos y la literatura de Aira: "y no voy a negar que uno de los mayores placeres del trabajo fue el de trabajar con la creencia, absoluta, sí, en ese cuento; después de todo, ¿no es maravillosa la experiencia de la creencia 'total' en un relato, y la de seguir leyendo, en consecuencia?" 
(CONTRERAS, 2003, p. 11). ${ }^{15}$ Para un grupo de estudiosos de la Universidad de Rosario abocados a la crítica de la obra de Aira, no es solo un objeto de estudio. Desde comienzos de los noventa entablan un vínculo personal. "Era como ir a hablar con Borges", cuenta Alberto Giordano en entrevista con la autora en 2019, reforzando la impresión de "la algarabía del descubrimiento" (RUBINICH, 1985, p. 44).

Estas tensiones reafirman la creencia en el valor literario que funda estos espacios. Aquellas ambivalencias, que llevan a definir la literatura como "algo heterogéneo (...) O al revés, quién sabe" (AIRA 1986, p. 8), llegan a exasperar a sus entrevistadores. En una entrevista para la revista La muela del juicio, Esteban López Brusa y Miguel Dalmaroni se defienden ante el desacuerdo de Aira con una afirmación de ellos: "Arrastrábamos una figura que vos usaste...” (AIRA, 1992, p. 10). Pero del mismo modo, poniendo en cuestión las posibilidades vigentes, Aira vuelve a centrar la mirada un proyecto literario que se desentiende de todo lo que le parece como exterior: si bien el escritor no se erige en figura pública, esto no desencanta su rol sino que abre posibilidades para explorar lo literario sin ninguna exigencia exterior; si bien la lógica del mercado gana preeminencia en la producción literaria, eso no ataca la calidad de la literatura, sino que supone la multiplicidad de espacios donde hacer circular los libros; si bien esa misma lógica del mercado editorial es una marca distintiva de su proyecto literario, la crítica y la academia (espacios que parecieran antagónicos al polo económico) también lo convierten en un objeto privilegiado de sus reflexiones.

En 1986 Aira escribe para Creación. La revista argentina para el nuevo siglo un texto en que reseña La posmodernidad de Hal Foster, La condición posmoderna de Jean-François Lyotard y El fin de la modernidad de Gianni Vattimo. Fiel a su estilo, Aira comienza por vislumbrar la contradicción: nota la imposición del posmodernismo como tema del ámbito intelectual, como sucede en otro momento con el estructuralismo o el existencialismo, y remarca la paradoja de hablar de moda para el caso del posmodernismo, que se propone como la superación de las modas. Incluso incluye una de sus adversativas: "La alternativa ante este giro que toman las cosas sería defender entonces la representación, y afirmar que la posmodernidad es el triunfo de la representación... o lo contrario..." (AIRA, 1986, p. 69). Aira percibe la transformación en las jerarquías y centralidades. Los "evangelistas de la posmodernidad" presentan un "recorte y montaje de preferencias" (AIRA, 1986, p. 69). Aira lo lee como ventaja: "ha impedido que apareciera un Padre posmodernista, y el legajo se mantiene abierto, sin textos sagrados" (AIRA

15 Analizo los vínculos entre la trayectoria de Aira y grupos de estudio de la Universidad Nacional de Rosario y la editorial Beatriz Viterbo en Riveiro, 2021. 
1986, p. 69). Frente a la "acumulación excesiva de cultura" a la que se llega en la posmodernidad, sólo restar "jugar con sus ruinas" (AIRA, 1986, p. 68).

\section{Referencias}

ABRAHAM, Tomás. Fricciones. Buenos Aires: Sudamericana, 2004.

AGUADO, Amelia. 1956-1975. La consolidación del mercado interno. In: DE DIEGO, J. L. (dir.). Editores y politicas editoriales en Argentina (1880-2010). Buenos Aires: Fondo de cultura económica, 2014. p. 135-171.

AIRA, César. "La literatura está fuera de la lengua, de lo humano." Entrevista realizada por Jorge Dorio. Tiempo cultura. Tiempo argentino, Buenos Aires, p. 8, 8 de mayo de 1983.

AIRA, César. "La novela tiene que ser como una marea de amor'." Entrevista realizada por Esteban López Brusa; y Miguel Dalmaroni. La muela del juicio VII, n 3, p. 7-11, 1992.

AIRA, César. "Si uno descubre que no es un genio, no se resigna a ser lo que viene después." Entrevista realizada por Francesc Relea." El país, España, 29 de junio de 2002. http://elpais.com/diario/2002/06/29/babelia/1025307550_850215. html. Acesso em: 16 de jul. 2021.

AIRA, César. "Solo aspiro a una gloria de bolsillo." Charla con el escritor argentino César Aira. Entrevista realizada por Diana Sperling. Cultura y nación. Clarín, Buenos Aires, p. 1-2, 11 de octubre de 1984.

AIRA, César. "Yo nunca usaría la literatura para pasar por buena persona." Entrevista realizada por A. Castro; y B. Borgna. Pie de página, Buenos Aires, nº 1, p. 2-3, 1982.

AIRA, César. Alejandra Pizarnik. 1936-1972. In: PIZARNIK, A. Alejandra Pizarnik. Vidas literarias. Barcelona: Ediciones Omega, 2001. p. 9-76.

AIRA, César. Arlt. Paradoxa. Literaturalfilosofía, Rosario, nº 7, p. 55-71, 1993 a.

AIRA, César. El discurso del "posmodernismo". Creación. La revista argentina para el nuevo siglo, Buenos Aires, v. 1, n 4, p. 68-69, 1986.

AIRA, César. Exotismo. Boletin/3. Grupo de estudios de Teoría Literaria, Buenos Aires, $\mathrm{n}^{\circ} 3$, p. 73-79, $1993 \mathrm{~b}$.

AIRA, César. "Vivir entre libros, mi vocación." Entrevista realizada por Adhemar Manjón. El Deber, 27 de agosto de 2016.

BORGES, Jorge Luis. Somos un país más bien desdichado. Cultura y Nación. Clarín, Buenos Aires, p. 2-3, 25 de febrero de 1982. 
BOSCHETTI, Anna. Ismes. Du realisme au postmodernisme. Paris: CNRS Éditions, 2014.

BOURDIEU, Pierre. Las reglas del arte. Génesis y estructura del campo literario. Barcelona: Anagrama, 2005.

CONTRERAS, Sandra. Intervención. Boletin/11 del Centro de Estudios de Teoría y Critica Literaria, Rosario, ${ }^{\circ} 11$, p. 1-13, 2003.

CONTRERAS, Sandra. Las vueltas de César Aira. Buenos Aires: Beatriz Viterbo, 2002.

DALMARONI, Miguel. El largo camino del "silencio" al "consenso". La recepción de Saer en la Argentina (1964-1987). In: SAER, J. J. y PREMAT, J. (coord.). Glosa. El entenado. Edición crítica. Poitiers: Université de Poitiers, Córdoba: Alción editora, 2010. p. 607-663.

DÁMASO MARTÍNEZ, Carlos. Ricardo Piglia. La novela como utopía. Suplemento cultural de La razón, Buenos Aires, p. 8-9, 15 de septiembre de 1985.

DE DIEGO, José Luis. ¿Quién de nosotros escribirá el Facundo? Intelectuales y escritores en Argentina (1970-1986). La Plata: Ediciones al margen, 2007.

DECOCK, Pablo. Las figuras paradójicas de César Aira. Un estudio semiótico y axiológico de la estereotipia y la autofiguración. Berna: Peter Land, 2014.

DUJOVNE, Alejandro. La máquina de traducir. Eudeba y la modernización de las ciencias sociales y humanas, 1958-1966. Papeles de Trabajo, nº 10 (18), p. 123-144, 2016 .

ESCALANTE GONZALBO, Fernando. A la sombra de los libros. Lectura, mercado y vida pública. México: El Colegio de México, Centro de Estudios Internacionales, 2007.

FALCÓN, Alejandrina. Hacia una historia de las traducciones y los traductores del Centro Editor de América Latina: el caso de la Biblioteca Básica Universal (1968/1978). El taco en la brea, n4 (5), p. 257-272, 2017.

GARCÍA NEGRONI, María Marta. El arte de escribir bien en español. Manual de corrección de estilo. Buenos Aires: Santiago Arcos, 2004.

GARCÍA, Mariano. Degeneraciones textuales: los géneros en la obra de César Aira. Rosario: Beatriz Viterbo, 2006.

HOPENHAYN, Silvia. Casi todo está permitido. Cultura. La nación, Buenos Aires, 10 de mayo de 1998.

IDEZ, Ariel. Literal. La vanguardia intrigante. Buenos Aires: Prometeo, 2010.

KOHAN, Martín. Lo más breve de lo breve. Las novelas ínfimas de César Aira. In: LAFON, M., BREUIL, C. y REMÓN-RAILLARD, M. (eds.). César Aira, une 
révolution. París: Tigre/Hors série. CERHIUS (ILCEA), Université StendhalGrenoble 3, LI.RI.CO-TRAVERSES, Université París 8, 2005. p. 79-86.

LADDAGA, Reinaldo. Una literatura de la clase media. Notas sobre César Aira. Hispamérica $\mathrm{n}^{\circ} 30$ (88), p. 37-48, 2001. http://www.jstor.org/stable/20540267. Acesso em: 16 de jul. 2021.

LIBERTELLA, Héctor. La arquitectura del fantasma. Una autobiografia. Buenos Aires: Santiago Arcos editor, 2006.

LO PRESTI, Flavio. El otro, el mismo. Ń. Clarín, 12 de enero de 2014.

MANZI, Joaquín. Argentinaira. In: LAFON, M., BREUIL, C. y REMÓNRAILlARD, M. (eds.). César Aira, une révolution. París: Tigre/Hors série. CERHIUS (ILCEA), Université Stendhal-Grenoble 3, LI.RI.CO-TRAVERSES, Université París 8, 2005. p. 209-225.

MARQUARDT, Eduard. A ética do abandono. César Aira e a nova escritura. (Tesis de posgrado). Centro de Comunicação e Expressão. Programa de Pós-Graduação em Literatura. Universidade Federal de Santa Catarina, Santa Catarina, 2008. https://repositorio.ufsc.br/xmlui/bitstream/handle/123456789/91287/255057. pdf?sequence=1\&isAllowed=y. Acesso em: 16 de jul. 2021.

MICELI, Sergio. Sueños de la periferia. Intelectualidad argentina y mecenazgo privado. Buenos Aires: Prometeo, 2017.

MONTALDO, Graciela. Borges, Aira y la literatura para multitudes. Boletin/6 del Centro de Estudios de Teoría y Crítica literaria, Rosario, nº 6, p. 7-17, 1998.

MONTALDO, Graciela. Un caso para el olvido: estéticas bizarras en la Argentina. El matadero, Buenos Aires, n 3, p. 37-50, 2004.

MONTALDO, Graciela. Vidas paralelas. La invasión de la literatura. In: LAFON, M., BREUIL, C. y REMON-RAILLARD, M. (eds.). César Aira, une révolution. París: Tigre/Hors série. CERHIUS (ILCEA), Univesité Stendhal-Grenoble 3, LI.RI.CO-TRAVERSES, Université Paris 8, 2005.

PÁGINA/12. “¿Cuánto vale un escritor?” Primer plano (Página/12), Buenos Aires, 16 de junio de 1991, p. 6-7.

PÁGINA/12. Noticias del mundo. Buenos Aires, 1999.

PÁGINA/12. Un antipremio a la poesía. Buenos Aires, 31 de diciembre de 1987.

PODLUBNE, Judith. César Aira: La lógica del continuo. Paradoxa. Literatural Filosofia X, nº 8, p. 59-71, 1996.

PREMAT, Julio. El idiota de la familia. In: LAFON, M., BREUIL, C. y REMONRAILLARD, M. (eds.). César Aira, une révolution. París: Tigre/Hors série. 
CERHIUS (ILCEA), Univesité Stendhal-Grenoble 3, LI.RI.CO-TRAVERSES, Université Paris 8, 2005. p. 79-86.

PRIETO, Julio. Vanguardia y mala literatura. De Macedonio a César Aira. In: LAFON, M., BREUIL, C. y REMÓN-RAILLARD, M. (eds.). César Aira, une révolution. París: Tigre/Hors série. CERHIUS (ILCEA), Univesité Stendhal-Grenoble 3, LI.RI.CO-TRAVERSES, Université Paris 8, 2005. p. 181-194.

REMÓN RAILLARD, Margarita. César Aira o la literatura del continuo. (Tesis de posgrado no publicada). Universidad Grenoble III - Stendhal. Grenoble, 1999.

RIVEIRO, María Belén. César Aira en entrevistas: la construcción de la figura de escritor (1981-2001). Trabajo y Sociedad, n³3, p. 83-101, 2019.

RIVEIRO, María Belén. César Aira y la grandeza menor: una tradición de escritores raros. Telar. Revista del Instituto Interdisciplinario de Estudios Latinoamericanos (IIELA) n 25, p. 149-166, 2020.

RIVEIRO, María Belén. Por una Sociología del espacio editorial: el caso de César Aira y Beatriz Viterbo editora como espacio de resistencia y libertad. Estudos de Literatura Brasileira Contemporânea, n 62, p. 1-19, 2021.

RUBINICH, Lucas. Retrato de una generación ausente. Punto de vista. Revista de cultura, Buenos Aires, v. VII, n² 23, 1985.

RUSSO, Miguel. El pase de Osvaldo Soriano de Sudamericana a Tesis. La Maga, Buenos Aires, 22 de marzo de 1995.

SAFERSTEIN, Ezequiel, SZPILBARG, Daniela. El espacio editorial “independiente”: heterogeneidad, posicionamientos y debates. Hacia una tipología de las editoriales en el período 1998-2010. En Actas del Primer Coloquio Argentino de Estudios sobre el Libro y la Edición. La Plata: Facultad de Humanidades y Ciencias de la Educación, Universidad Nacional de La Plata, 2012. 464-484. http://coloquiolibroyedicion. fahce.unlp. edu.ar/actas/Szpilbarg. Acesso em: 16 de jul. 2021.

SAÍTTA, Sylvia. Una novela de Aira. Los diarios del viaje. Revista de politica y cultura, Buenos Aires, $\mathrm{n}^{\circ}$ 1, 1988.

SPERANZA, Graciela. César Aira: Manual de uso. Milpalabras. Letras y artes en revista, $\mathrm{n}^{\circ} 1$, p. 2-13, 2001.

SPERLING, Diana. "Solo aspiro a una gloria de bolsillo." Charla con el escritor argentino César Aira. Cultura y nación. Clarín, Buenos Aires, 11 de octubre de 1984.

STRAFACCE, Ricardo. De la agrimensura a la decoración de ambientes (Literatura, Estado y representación en Kafka). El rodaballo. Revista de politica y cultura, IV, $\mathrm{n}^{\circ} 8$, p. 51-55, 1998. 
STRAFACCE, Ricardo. César Aira, un catálogo. Buenos Aires: Mansalva, 2008a.

STRAFACCE, Ricardo. Osvaldo Lamborghini, una biografía. Buenos Aires: Mansalva, 2008 b.

VANOLI, Hernán. La buena estrella de César Aira. Crisis, n5, Buenos Aires, 2011. http://www.revistacrisis.com.ar/La-buena-estrella-de-Cesar-Aira.html. Acesso em: 16 de jul. 2021.

VECCHIO, Diego. Procedimientos y máquinas célibes. Roussel, Duchamp, Aira. In: LAFON, M., BREUIL, C. y REMON-RAILLARD, M. (eds.). César Aira, une révolution. París: Tigre/Hors série. CERHIUS (ILCEA), Univesité StendhalGrenoble 3, LI.RI.CO-TRAVERSES, Université Paris 8, 2005. p. 167-180.

María Belén Riveiro es Licenciada en Sociología y Doctora en Ciencias Sociales por la Universidad de Buenos Aires. Becaria posdoctoral del CONICET con sede de trabajo en el Instituto de Investigaciones Gino Germani (FSOC-UBA). Docente de Sociología General (FSOC-UBA). Miembro del "Grupo de Estudios de Sociología de la Literatura" (IIGG-UBA) y del "Programa Mundo editorial, lectura y traducción desde los estudios de género(s) y feminismos" (Laboratorio Interdisciplinario de Ciencias Humanas - CONICET). Publicaciones recientes son "Sobre los inicios de una trayectoria literaria: el caso de César Aira en publicaciones periódicas desde una mirada sociológica" (Hallazgos); "Tres reflexiones sobre la sociología de la literatura" (Políticas de la memoria); y "Ada Korn editora: por una historia crítica del mundo editorial" (Cuadernos del Centro de Estudios en Diseño y Comunicación).

E-mail: mbriveiro@sociales.uba.ar 